\title{
As Transições Familiares do Divórcio ao Recasamento no Contexto Brasileiro
}

\author{
Family Transitions: From Divorce to Remarriage in the Brazilian Context
}

\author{
Débora Staub Cano*, Leticia Macedo Gabarra, Carmen Ocampo Moré \& Maria Aparecida Crepaldi \\ Universidade Federal de Santa Catarina
}

\begin{abstract}
Resumo
Este artigo tem como objetivo fazer considerações teórico-metodológicas sobre o tema do divórcio e do recasamento, apresentando as metodologias utilizadas em pesquisas nesta área e identificando novas possibilidades de estudos e intervenções. Para tanto, descrevem-se o panorama do divórcio no Brasil e as pesquisas encontradas nesta área, examinando os fatores relacionados com o processo de separação, o impacto associado a essa transição nas famílias, assim como o período de pós-divórcio e de recasamento. Considerase que existem lacunas a ser preenchidas com novos estudos, de modo que se sugere a realização de pesquisas envolvendo o processo de divórcio e recasamento nos diferentes momentos do ciclo vital da família, bem como sobre a fratria dos filhos de casais divorciados, sobre as variadas configurações familiares e sobre a rede de apoio a essas famílias.

Palavras-chave: Divórcio; Pós-divórcio; Recasamento.

Abstract

This article aims at making theoretical and methodological considerations about divorce and remarriage, presenting used research methods and identifying new approaches for studies and intervention in the area. In doing so, the general view of divorce in Brazil is described, as well as studies found in the area, examining the factors that are related to the break-up process, family transition impacts, and post-divorce and remarriage periods. It is considered that there are still some gaps which need to be filled up with new findings. It is also suggested the accomplishment of new researches in different family life cycles involving the processes of divorce and remarriage as well as the brotherhood relationship of divorced parents, other family organizations, and the social networks of such families.

Keywords: Divorce; Post-divorce; Remarriage.
\end{abstract}

O divórcio no Brasil foi regulamentado apenas em 1977, sendo que, até então, não era juridicamente possível postular um novo casamento ${ }^{1}$. De fato, o divórcio e o recasamento já ocorriam, antes mesmo da regulamentação pela via de lei. Porém, não eram reconhecidos ou aceitos socialmente, constituindo temas velados ou evitados nas redes sociais e familiares.

A modificação na lei evidenciou os diversos modelos e padrões de família, tais como aqueles padrões socialmente esperados da família nuclear, ou ainda, os "novos" modelos familiares, decorrentes de reorganizações conjugais, separações, novas formas de união e recasamento.

Dados do Instituto Brasileiro de Geografia e Estatística ([IBGE], 2007) mostram que os números de divórcio e separações ocorridos no Brasil, entre os anos de 1993 e 2003,

* Endereço para correspondência: Universidade Federal de Santa Catarina, Departamento de Psicologia, Laboratório de Psicologia da Saúde, Família e Comunidade, Campus Universitário Trindade, Florianópolis, SC, Brasil, CEP 880409000.Email: deborascano@hotmail.com

${ }^{1}$ Lei 6.515 , de 26 de dezembro de 1977, que "Regula os casos de dissolução da sociedade conjugal e do casamento, seus efeitos e respectivos processos, e dá outras providências". Esta lei entrou em vigor na data da publicação, ou seja, em 27 de dezembro de 1977. cresceram $44 \%$ e $17,8 \%$, respectivamente ${ }^{2}$. Já no período entre 2004 e 2005, as separações judiciais aumentaram $7,4 \%$, mantendo um crescimento gradativo. Destaca-se que os números do IBGE não incluem as uniões e as dissoluções consensuais, mas, a partir deles, é possível pressupor que, se fossem considerados os dados extra-oficiais, as estatísticas seriam ainda maiores. Tendo em conta esses dados e o contexto sócio-histórico atual do segundo milênio, o divórcio tornou-se evidente, razão pela qual surge a necessidade de mais pesquisas nacionais sobre o tema para subsidiar uma reflexão contextualizada à realidade brasileira.

Peck e Manocherian (1980/2001) destacam que, apesar da prevalência do divórcio, os membros da família, em geral, não estão preparados para o impacto emocional, social e econômico que o mesmo acarreta. Nesse sentido, tais autores argumentam que a transição da separação conjugal afeta a família em várias gerações, aumentando a complexidade das tarefas desenvolvimentais vivenciadas. 
Associado a isso, e tendo em conta as contribuições da psicologia do desenvolvimento e de teóricos da família (Carter \& McGoldrick, 1980/1995; Cerveny, 2002), constata-se que tanto o indivíduo quanto a família apresentam um ciclo vital de desenvolvimento, com estágios diferenciados no que diz respeito às aquisições de tarefas específicas dos mesmos. Assim, a família e o indivíduo se desenvolvem segundo uma seqüência de eventos - na qual alguns episódios são considerados esperados, e outros, imprevisíveis (ditos "não normativos"). Essas ações imprevisíveis, por sua vez, impõem novos desafios e novas reorganizações tanto para a família quanto para o indivíduo, de modo que se afetam recursivamente. O conhecimento que se postula proporciona a identificação de pontos de transição de um estágio para o outro no desenvolvimento da família (Hetherington, 1991).

Nesses ciclos de desenvolvimento, quando o assunto é divórcio, verifica-se que não existe um consenso sobre se se trata de um evento normativo ou não normativo. Autores como Carter e McGoldrick (2003), observando o desenvolvimento da família em termos históricos, afirmam que o número de divórcios na última década, na sociedade americana, permite dizer que o mesmo pode ser compreendido como um evento normativo, dada sua alta incidência.

Em uma análise da literatura brasileira (nos seguintes bancos de dados: Index-Psi, Scielo, BSV-PSi e Pepsic, utilizando-se os descritores, divórcio, recasamento e transições familiares) foram encontrados apenas 36 artigos, distribuídos ao longo de 23 anos (1984 a 2007). Concluise, pois, que há uma escassez de estudos nessa área no Brasil, no domínio da psicologia. Esses artigos tratam de questões diversas sobre o divórcio e o recasamento, que serão abordadas ao longo deste texto. Serão utilizados, também, trabalhos internacionais clássicos e outros mais recentes, para contextualizar a temática.

Assim sendo, o presente artigo tem como objetivo elucidar questões teórico-metodológicas sobre divórcio e recasamento, ainda que de forma introdutória, percorrendo, desse modo, tópicos como: o divórcio no Brasil, um panorama social; os fatores relacionados a esse processo; o seu impacto nas famílias; e como se configuram as famílias pós-divórcio e famílias recasadas. Com base na literatura, portanto, este artigo busca promover uma discussão a partir de pesquisas e dados brasileiros, a fim de compreender o estado da arte desse tema, bem como identificar lacunas a serem pesquisadas e diferentes possibilidades metodológicas. Pretende-se, pois, dar respaldo teórico e científico para as intervenções, tanto dos psicólogos, quanto dos outros profissionais que trabalham com famílias.

\section{Divórcio}

\section{Um Panorama no Brasil}

A palavra "divórcio" vem do latim divortium, que quer dizer "separação", que por sua vez é derivada de divertere, que significa "tomar caminhos opostos, afastar-se". Nesse contexto de significações, entende-se o divórcio como um processo que ocorre no ciclo vital da família, desafiando sua estrutura e sua dinâmica relacional. Conforme Cerveny (2002), a separação do casal não acaba com a família, porém a transforma. Em outras palavras, a estrutura se altera com a dissolução da conjugalidade, embora a família, enquanto organização, se mantenha.

Juridicamente, a separação judicial põe termo aos deveres de coabitação, fidelidade recíproca e ao regime matrimonial de bens, como se o casamento fosse dissolvido (conforme art. $3^{\circ}$ da Lei 6.515, 1977). Entretanto, convém salientar que a separação não extingue o casamento; ela estabelece um tempo, de, no mínimo, um ano, para que os cônjuges decidam o que realmente almejam. Por sua vez, o divórcio marca a dissolução do casamento, ou seja, a separação do marido e da mulher, conferindo às partes o direito de novo casamento civil.

Féres-Carneiro (2003) aponta que, na sociedade contemporânea, os divórcios aumentaram, porém isso não significa o desprezo ao casamento, mas, ao contrário, sua valorização. A autora parte da hipótese que o casamento ainda é uma instituição fundamental para a maioria das pessoas, pois quando o matrimônio não corresponde às expectativas do casal, ocorre o divórcio. Nesses termos, as pessoas se divorciam porque esperam mais de seus casamentos, iniciando, então, uma busca por novas relações e, se possível, outro casamento. Essa conjetura vai ao encontro da suposição do IBGE (2007) de que o número de homens requerentes no processo de divórcio esteja aumentando devido ao interesse no recasamento, haja vista o crescente índice de homens divorciados que casam novamente.

As mulheres, por sua vez, ainda são as que mais solicitam a separação, considerando-se tanto a separação judicial $(72 \%)$ quanto o divórcio $(53,4 \%)$. Esse dado pode ser confirmado por pesquisa realizada por Féres-Carneiro (2003), em uma amostra incluindo homens e mulheres das camadas médias da população do Rio de Janeiro. Por meio de entrevistas semi-estruturadas, que visavam a investigar como esses sujeitos vivenciaram o processo de dissolução do casamento e reconstruíram suas identidades após a separação, a autora evidenciou que a decisão de separar-se é, na grande maioria dos casos, uma decisão das mulheres, sendo que os homens confirmaram esse resultado em suas percepções. Outro aspecto ressaltado é o de que, mesmo que a decisão de separação seja predominantemente feminina, são as mulheres que tomam a maior parte das iniciativas de diálogo, buscando alternativas para o relacionamento.

Em face dessa abordagem, há que se considerar que a tomada de decisão por separar-se é multi-determinada. Ademais, a expectativa com relação ao casamento, o que esperam da relação, o que imaginam, é vivenciada de maneira distinta para os cônjuges (Féres-Carneiro, 1997). Isso pode ser demonstrado por pesquisas (Féres-Carneiro, 1995, 1997, citada por Féres-Carneiro, 2003; Magalhães, 1993) que relatam que a concepção de casamento para os homens está relacionada com a "constituição de família", enquanto que, para as mulheres, o casamento é concebido como "relação amorosa". 
Conforme dados do IBGE (2007), na maioria dos casos de divórcio, os filhos ficam sob a custódia da mãe $(89,5 \%)$. Apesar disso, convém ponderar que, do ponto de vista legal, foi recentemente estabelecida no Brasil a guarda compartilhada ${ }^{3}$, que determina "a responsabilização conjunta e o exercício de direitos e deveres do pai e da mãe que não vivam sob o mesmo teto, concernentes ao poder familiar dos filhos comuns instituindo responsabilidades"4. A guarda compartilhada ainda é rara, abrangendo somente $2,9 \%$ dos divórcios. Apesar disso, é possível supor que, cada vez mais, o movimento pela guarda compartilhada aumente, em função não apenas da alteração legal registrada, mas, especialmente, da maior democratização nas relações entre homens e mulheres e a crescente reivindicação dos homens a um papel mais ativo na criação dos filhos.

Com relação à guarda dos filhos, Féres-Carneiro (2003) evidencia que existe uma diferença na percepção de homens e mulheres em relação aos filhos após o divórcio. A autora salienta que as mulheres percebem seus filhos "sem tantos problemas", até mesmo porque elas convivem mais com os mesmos e se encontram mais presentes no cotidiano deles. Os homens, por sua vez, tendem a perceber os filhos com mais dificuldades e problemas em frente ao processo de separação, uma vez que, por estarem mais ausentes no dia-a-dia, tendem a projetar nos filhos suas próprias dificuldades e o sofrimento decorrente da ausência causada pela separação.

No Brasil ${ }^{5}$, a duração média dos casamentos é de dez anos e meio, sendo que os cônjuges, na época de dissolução, têm, em média, mais de trinta anos. No entanto, essa média de tempo apresentada não deixa claro qual é o desvio padrão entre o menor e o maior tempo de duração do casamento. Desse modo, a referida amostra tanto pode ser homogênea, como pode apresentar uma dispersão muito grande, ou seja, pode ser composta tanto por casamentos com mais de quinze anos quanto por casamentos curtos, com duração de dois a três anos, por exemplo, o que faz grande diferença ao se pensar o impacto do divórcio gerado nas famílias.

A partir desses dados, pode-se inferir o quanto, na atualidade, a família vem se reconfigurando em decorrência dessas transições e de mudanças sociais que alteram a sua organização. Ainda com base em dados do IBGE (2007), denota-se a incidência do crescimento de famílias monoparentais, pois os índices apontam que, em 47\% dos domicílios, um dos pais está ausente da constituição familiar. Diante dessas considerações, há que se pensar quais são os outros aspectos que estariam concorrendo para que esses índices se configurem como tal, o que será discutido a seguir.

${ }^{3}$ Lei $\mathrm{n}^{\circ} 11.698$, de 13 de junho de 2008, que "Altera os arts. 1.583 e 1.584 da Lei no 10.406 , de 10 de janeiro de $2002-$ Código Civil, para instituir e disciplinar a guarda compartilhada".

${ }^{4}$ Nos termos do $§ 1^{\circ}$, do art. 1.583 , do Código Civil, alterado pela Lei 11.698 , de 13 de junho de 2008 .

${ }^{5}$ Dados do IBGE (2007).

\section{Fatores Relacionados ao Processo de Divórcio}

Peck e Manocherian (1980/2001) apontam que, entre alguns fatores etiológicos relacionados à incidência do divórcio, encontram-se: a diferença de status socioeconômico (quando a mulher ganha mais, instabilidade de renda e do emprego do marido); o menor grau de instrução do homem (quando comparado com a sua esposa); a idade dos cônjuges (quanto mais jovens, mais alta é a incidência); a ocorrência de gravidez pré-nupcial; a diferença racial, e as questões de gênero.

A respeito da idade dos cônjuges, esse dado é evidenciado por uma pesquisa brasileira (Féres-Carneiro, 2003) em que os entrevistados a apontam como um fator que dificulta o relacionamento conjugal, em função de opinarem que se casaram muito cedo (com menos de vinte e três anos). Inclusive, em alguns discursos, isso fica evidente quando os entrevistados relatam terem se sentido ainda adolescentes e imaturos para assumir as responsabilidades do casamento.

Ao se analisar o fator referente às diferenças de gênero, percebe-se que a luta do movimento feminista e toda a questão que envolve a igualdade de possibilidades entre os sexos acaba, de uma maneira ou de outra, influenciando no divórcio. A modificação do papel da mulher no mundo ocidental é citada como um dos fatores que interferiram no crescimento do número de divórcios (C. Araújo \& Scalon, 2006; Biasoli-Alves, 2004; Goldani, 2002). A entrada no mercado de trabalho, atrelada à possibilidade de que a mulher se auto-sustente e conquiste a sua independência financeira, possibilitou maior autonomia nas escolhas amorosas femininas. Afinal, se antes as esposas dependiam financeiramente do cônjuge varão, muitas vezes se percebendo impossibilitadas de optar pela separação, atualmente se evidencia que é mais remota a chance de que elas permaneçam casadas por questões financeiras (Goldenberg, 2003). Para corroborar esse fato, alguns autores descrevem o crescente número de mulheres que são chefes de família, proporcionando o sustento financeiro de todos os membros (Fleck \& Wagner, 2003; Testoni \& Tonelli, 2006).

Essa questão é salientada por Biasoli-Alves (2004), que sustenta que o trabalho das mulheres fora do ambiente doméstico acarretou diversas alterações na vida familiar, elevando a importância de valores democráticos e produzindo alterações significativas na família e no casamento. As mulheres, segundo a autora, apresentam-se menos dispostas a terem uma prole numerosa, para serem mais "livres" e ganharem maior autonomia no processo de escolha do companheiro, evidenciando, com isso, um maior grau de liberdade com menos interdições e sujeições ao cônjuge.

Há que se considerar, também, que esse fato diz respeito a apenas uma determinada classe social, pois outro fator que interfere no processo de divórcio e de separação é o atinente à pertença sócio-econômica e cultural dos cônjuges. Verifica-se, mais comumente, que, em camadas populares, a separação imprime configurações familiares diferentes daquelas de camadas médias e altas. Em populações de baixa renda, muitas vezes devido a questões financei- 
Cano, D. S., Gabarra, L. M., Moré, C. O. \& Crepaldi , M. A. (2009). As Transições Familiares do Divórcio ao Recasamento no Contexto Brasileiro.

ras, que impedem o casal de manter duas casas separadas, o divórcio inaugura um modelo familiar baseado em redes de ajuda mútua, em que mais de uma família residem juntas. Existem também situações em que se observam famílias monoparentais, chefiadas por mulheres com filhos de diferentes relacionamentos (Fonseca, 2004). A alteração do padrão econômico, com o divórcio, é recorrente, como nos resultados da pesquisa de Souza (2000).

Ainda no que tange à questão de gênero e de como os papéis dos cônjuges foram sendo (re)construídos socialmente no decorrer dos anos (especialmente em face de qual seria o papel esperado da mulher e do homem no casamento), evidencia-se que as pesquisas legitimam as diferenças. Em trabalho citado anteriormente (Féres-Carneiro, 2003), foi verificado que a traição masculina aparece como causa da maior parte das separações e, conforme é colocado (Goldenberg, 2000, citado por Féres-Carneiro, 2003), há uma diferença de sentimentos em relação à infidelidade, haja vista que são as mulheres as que relatam sentimentos de culpa pela traição.

Goldenberg (2001) reflete que, apesar das transformações nos papéis masculinos e femininos, até o momento presente se constata a permanência de estereótipos sobre os sexos, como o do homem "galinha" e da mulher vítima, indefesa e frágil. Nesse sentido, Goldenberg $(2001,2003)$ pontua que essas transformações ocorrem de forma processual, havendo a coexistência dos papéis tradicionais do masculino e do feminino com "novas" representações de gênero, em que outros atributos são considerados, como o do homem sensível e frágil e da mulher independente e autônoma. Essas transformações interferem nas relações conjugais, mudam as exigências da conjugalidade e provocam novos desafios e dificuldades, o que muitas vezes ocasiona o divórcio.

Apesar dos diferentes fatores que corroboram para que ocorra o processo de divórcio, há que se considerar que, dependendo da cultura, da época e dos valores sociais compartilhados, esse processo acaba sendo vivenciado de outras formas. Ademais, há que se levar em consideração a fase do ciclo vital em que a família se encontra quando da ocorrência do divórcio.

\section{Impacto do Divórcio nas Famílias}

Pesquisadores na área de família ressaltam que o divórcio é um processo complexo, pluridimensional e que ocorre de forma diferenciada em cada família (Féres-Carneiro, 2003; Schabbel, 2005). Sobre o tema, Peck e Manocherian (1980/2001) destacam que o período de crise decorrente da separação do casal afeta todos os membros da família, porém de forma individualizada. Logo, o divórcio é um processo singular, haja vista que ele terá maior ou menor impacto nas pessoas envolvidas dependendo de alguns fatores (econômico, social, cultural, religioso), e, ainda, das redes de apoio que se estabelecem ou não. Disso decorrem os diferentes graus de complicações que envolvem a família.

Somado a esses fatores, evidencia-se o momento do ciclo vital em que a família se encontra, o que também imprime outras peculiaridades à separação. Peck e Manocherian (1980/2001) descrevem o impacto que a família pode sofrer em cada uma das fases: divórcio em recém casados, em famílias com filhos pequenos, com filhos adolescentes, com filhos jovens, e em casais no estágio tardio de vida.

Conforme Peck e Manocherian (1980/2001), o divórcio em recém casados é visto como o de melhor resolução, uma vez que envolve menos tempo de convívio e poucos laços familiares. Salientam que começar a vida de novo é menos difícil, uma vez que ambos têm experiências recentes de como é ser solteiro. Outro aspecto importante é que, muitas vezes, o casamento pode ter sido uma tentativa de independência, de um ou ambos os cônjuges, uma forma de 'sair de casa', ou, ainda, de se diferenciar da família de origem. Assim, de fato, as questões pendentes e não resolvidas, em sua maioria, referem-se à família de origem, e não à família recém constituída. Ressalta-se que esses autores se referem aos casais jovens com pouco tempo de casados, e não aos casamentos longos e sem filhos, cujo impacto nos cônjuges seria diferenciado dos primeiros.

As famílias com filhos pequenos têm dificuldade na comunicação sobre a decisão de separação do casal, o que pode gerar confusão para os filhos sobre o que está acontecendo. Freqüentemente, a falta de comunicação intrafamiliar ocorre pela idéia de que falar pode prejudicar a criança, de modo que os filhos mantêm o silêncio, que é compreendido pelos pais como ausência de dificuldades (Souza, 2000).

Souza (2000) entrevistou quinze adolescentes que vivenciaram a separação dos pais durante a infância. Em relação ao período em que o evento ocorreu, dez participantes relataram que identificaram o conflito conjugal, e cinco, que não o fizeram. O marco da separação para as crianças foi a saída do pai de casa. Os sentimentos recorrentes entre eles foram de tristeza, angústia, raiva e medo do que poderia acontecer. No entanto, reconheceram que a separação foi uma solução para as dificuldades da família.

Em pesquisa realizada para compreender como crianças e pré-adolescentes concebem as modificações, no ciclo de vida familiar, decorrentes da separação e de novas uniões parentais, Ramires (2004) salienta que quanto menores são as crianças, mais elas apresentam desejos e fantasias de terem a família novamente reunida, ao passo que as crianças com idade escolar, geralmente as mais vulneráveis, apresentam queixas escolares, profundo sentimento de perda, dor e pesar.

Conforme Ramires (2004), a qualidade dos vínculos constituídos se torna um elemento importante no fator de resiliência ${ }^{6} \mathrm{em}$ frente às transições familiares. Do mesmo modo, quanto maior o desenvolvimento cognitivo, afetivo e social, 
melhor a capacidade de enfrentamento das crianças e adolescentes, favorecendo, dessa forma, os mais velhos.

Pesquisas (Nock, 1981; Peck \& Manocherian, 1980/2001; Wendt, 2006) mostram uma maior ocorrência de separações e divórcios em famílias no período da transição para a parentalidade, ou seja, no período que se desenrola desde o nascimento do primeiro filho até os dezoito meses deste. Essa deve ser considerada uma transição normativa, universalmente aceita e que precisa ser estudada principalmente a partir do modo como o nascimento da criança afeta os padrões de interação do casal e a evolução dos mesmos na família (Nock, 1981). Os autores pontuam que isso ocorre em função de problemas conjugais anteriores ao nascimento dos filhos, que se intensificam com as novas tarefas desenvolvimentais da família (Peck \& Manocherian, 1980/2001; Wendt, 2006).

Os filhos pré-adolescentes, amiúde, assumem o papel de cuidadores em relação às figuras parentais, adotando atitudes de cuidado e proteção (Ramires, 2004). Já os filhos adolescentes que vivenciam a separação conjugal dos genitores necessitam lidar com uma carga adicional, pois, além das dificuldades inerentes à transição da adolescência, vivenciam a crise familiar ocasionada pelo divórcio. Nesse período, geralmente, as dificuldades familiares se acentuam entre pais e filhos, porque ambos os pólos estão passando por questões semelhantes, que dizem respeito a independência, sexualidade e novos relacionamentos.

Os casais com filhos jovens que saíram de casa cedo passam a priorizar a conjugalidade e têm maior liberdade para optar pela separação. A ocorrência de uma separação nessa fase do ciclo vital faz com que os filhos, que, na sua maioria, já estabeleceram relacionamentos estáveis, passem também a se preocupar com suas relações amorosas, uma vez que o modelo familiar de conjugalidade foi desfeito.

Quando as separações ocorrem no estágio tardio de vida, costumam ser um choque para a família, por causa da ruptura de um vínculo que todos esperavam que fosse "para sempre". Isso causa surpresa e espanto e, em regra, envolve mais de duas gerações, redefinindo, conseqüentemente, os valores morais de todos os seus membros (Peck \& Manocherian, 1980/2001).

Entretanto, além da fase do ciclo vital em que a família se encontra, há que se considerar, conforme Travis (2003), as expectativas do casal. Mesmo que as mudanças sejam desejadas, no caso do divórcio, elas envolvem perdas e sofrimentos, pois muitas coisas que foram importantes para os envolvidos no processo são deixadas pra trás. Autores como Ahrons (1980) e Hetherington (1991) propõem um período de dois a três anos até que ocorra um processo de ajustamento pós-divórcio, no qual se possa considerar que ocorreu certa homeostase familiar.

Souza e Ramires (2006) salientam que o divórcio é um processo de crise e ruptura no qual a família busca novas respostas e que isso não pode ser confundido com problemas de ajustamento ou de saúde mental. As autoras confirmam que o período envolve tensão e sofrimento, porém, em longo prazo, os efeitos negativos não são tão freqüentes como supunham.
Na prática clínica de terapeutas de família, a separação conjugal aparece como uma das transformações mais freqüentes, e é de consenso considerar esse processo e suas conseqüências como um evento familiar mais facilmente assimilado hoje do que alguns anos atrás (Travis, 2003). Conforme dados levantados pela autora, atualmente os filhos de pais separados são mais aceitos e socialmente amparados por colegas e pela escola do que em anos idos, quando havia maior preconceito.

Com o passar do tempo, o divórcio pode ser benéfico para os membros da família, que percebem uma melhora na qualidade de vida, tanto dos ex-cônjuges como dos filhos. Assim como, passada a crise inicial, os ex-cônjuges tendem a valorizar a sua liberdade, os sentimentos de autovalorização e autonomia (Wagner \& Féres-Carneiro, 2000). Desse modo, percebe-se que o processo acaba contribuindo para a resiliência dos membros da família, muitas vezes favorecendo o amadurecimento emocional dos pais, o que acarreta conseqüências positivas para os filhos.

Portanto, se o processo de separação é vivenciado de modo a possibilitar esse amadurecimento emocional, em que a própria situação e os conflitos possam ser resolvidos sem isenção de sofrimento e pesar, pode-se dizer que os cônjuges estarão mais preparados para novos relacionamentos, isso é, mais 'livres', no sentido de terem menos pendências com suas relações passadas.

\section{Famílias Pós-Divórcio e Recasamentos}

Nos últimos anos, houve um considerável número de alterações nos padrões do ciclo de vida familiar, entre as quais se citam o menor índice de natalidade, as mudanças no papel da mulher, o aumento da expectativa de vida e, como já foi afirmado, o aumento no índice de divórcios e recasamentos, imprimindo outras configurações e desafios para o sistema familiar em termos de tarefas a serem enfrentadas (Ahrons, 2007; Carter \& McGoldrick, 1980/1995; Fonseca, 2004). Desse modo, pode-se considerar que o divórcio e o recasamento, de fato, são elementos que alteram diretamente a estrutura e a dinâmica familiar, modificando padrões sociais e proporcionando outras configurações familiares à sociedade.

Com relação ao processo de divórcio, Brown (1980/2001) o divide em três fases: a primeira compreende o primeiro ano após a separação, conformando um período de caos, confusão e crise; a segunda, o realinhamento, caracterizase por ser uma fase de transição, em que as questões econômicas, sociais e extrafamiliares vão sendo reorganizadas entre o segundo e terceiro ano após a separação; e, por fim, a fase da estabilização, na qual se poderia dizer que, com efeito, há uma reorganização do sistema familiar.

O processo pós-divórcio engloba inúmeros ajustamentos, envolvendo desde a família de origem até a família extensa, incluindo amigos e comunidade/sociedade. Visher e Visher (1988) oferecem uma importante contribuição ao destacar que a família recasada é uma família que se constituiu de perdas, de modo que é muito importante que as mesmas sejam reconhecidas e também elaboradas. Salientam, com isso, a importância do processo terapêutico de 
modo a auxiliar os casos em que esta resolução não é vivida de forma satisfatória. Nazareth (2004), citada por Cerveny (2002), ressalta que toda separação tem consequiências para os envolvidos, e mesmo as separações desejadas, decorrentes de anos de insatisfação e sofrimento, acarretam sentimentos de perda, solidão, vazio e tristeza, características que permeiam o período pós-divórcio.

Quando esse processo não é satisfatoriamente resolvido, tende a ocasionar conflitos de diversas ordens, e também 'guerras' judiciais. É premente, portanto, a necessidade de auxílio profissional, seja de terapeutas familiares ou, fenômeno recente, de mediadores. A mediação visa a melhorar a capacidade de diálogo para alcançar uma solução mais afável para os conflitos (Schabbel, 2005).

O período imediatamente após a separação implica em várias mudanças para os membros da família. Os adolescentes entrevistados por Souza (2000) referiram-se às mudanças na vida, isto é, mudanças de moradia, de cidade, de escola, de transporte escolar, enfim, mudanças na rotina diária, e, ainda, mudanças nos relacionamentos - com os pais e com os irmãos. Relataram, ademais, aproximação e/ ou afastamento da família materna e paterna, afastamento de amigos do pai e/ou da mãe, e perda de amigos. A autora ressalta que a situação do divórcio dos pais envolve inúmeras perdas, o que gera alterações na rotina diária, tanto das crianças, quanto dos adultos.

O apoio oferecido pela família extensa, pelos amigos e pela escola é fundamental nesse processo após o divórcio, sendo considerada toda a rede de apoio social da família. M. R. G. L. Araújo e Dias (2002) investigaram o apoio oferecido pelos avós aos netos após a situação de separação dos pais. Essas autoras dividiram o tipo de suporte oferecido em: (a) emocional, que incluía ações de acarinhar, aconselhar, visitar, passear e dar informações; e (b) instrumental, isto é, que compreendia a ajuda financeira, o preparo de refeições, e a ajuda para se alimentar e elaborar tarefas escolares. Os resultados dessa pesquisa indicaram uma preferência dos avós pelas atividades emocionais, notando um aumento da mesma após o período de separação. Nesses achados, destaca-se a importância da família extensa no período de transição pós-divórcio.

A reorganização da vida familiar demora alguns anos. Na pesquisa de Souza (2000), por exemplo, os adolescentes referiram o período entre dois e quatro anos para essa reorganização ocorrer. Nesse estudo, os participantes consideraram positiva a redução dos conflitos e o estabelecimento de uma relação positiva entre os pais, a compreensão das conseqüências da separação em suas vidas, e as novas relações conjugais dos pais. Mas, por outro lado, destacaram a perpetuação do conflito no sistema de guarda, pensão e visitas, a superproteção materna ou da família extensa, e, do mesmo modo, as novas relações conjugais dos pais. A autora reflete que os novos parceiros parentais podem tanto ser considerados sob o aspecto positivo, como negativo.

Quando se fala de família, por mais que se relativizem os conceitos e os termos utilizados, geralmente a idéia ainda está muito associada à imagem de pai, mãe e filhos. Travis (2003) enfatiza que na literatura sobre recasamento há uma posição e um status diferenciado para a família nuclear, enquanto que às famílias reconstituídas caberia uma posição de menor destaque. Entretanto, nos dias de hoje, já não é tão incomum ouvir descrições de outros padrões e diferentes organizações familiares.

Conforme trazem Souza e Ramires (2006), as crianças e os adolescentes atualmente podem, em função dessas modificações familiares, responder de uma maneira muito inusitada a uma pergunta simples. Por exemplo, à questão "Você tem irmãos?", ao invés dos esperados "sim" ou "não", a resposta pode ser "depende". As autoras argumentam que, em função de recasamentos e novas uniões, os filhos passam hoje a conceber a família de outras formas, algumas vezes incluindo meios-irmãos, outras vezes considerando apenas a família nuclear, segundo uma vasta possibilidade de rearranjos.

As novas configurações familiares também foram observadas na pesquisa realizada por Wagner e Féres-Carneiro (2000). As autoras pesquisaram adolescentes provenientes de famílias originais (FO) ou intactas, isso é, compostas por pai, mãe e filhos biológicos, e famílias reconstituídas (FR), ou seja, aquelas em que os pais eram separados do primeiro cônjuge e mantinham uma relação estável com um novo companheiro há, no mínimo, seis meses, coabitando com os filhos do primeiro casamento. Nessa pesquisa, os participantes realizaram a representação gráfica da família. Do total, 45,7\% dos adolescentes de FR desenharam os membros que coabitavam no momento atual, considerando os novos membros da família. As autoras concluíram que as variáveis coabitação, consangüinidade e tempo de recasamento foram as mais importantes na definição dos núcleos recasados.

Travis (2003), em pesquisa realizada com terapeutas de família e que tinha como objetivo verificar as percepções destes acerca do recasamento, evidenciou que eles têm dificuldades em definir a família, devido à variedade de modelos existentes e socialmente aceitos na atualidade. Assim, refletir sobre o recasamento envolve considerar diferentes padrões familiares.

A palavra recasamento está longe de ser a melhor expressão para designar esta nova união, haja vista que o uso do prefixo "re" traz a idéia de repetição, de reformulação e de recriação, o que, por sua vez, nos remete a pensar em remendo e reconstituição, trazendo uma conotação negativa, como se antes existisse uma união mais original ou verdadeira. Desse modo, a família nuclear é ainda vivenciada como mais valorizada e legítima, como se o que fugisse a esse padrão fosse de menor valor (Brun, 1999, citado por Travis, 2003).

Ao considerar-se os dados brasileiros, com base no IBGE, verifica-se que, somente no ano de 1994, foram registrados 29.690 casamentos entre divorciados e solteiras, 11.528 entre divorciadas e solteiros, e 5.867 entre divorciadas e divorciados (IBGE, 1994). A proporção de casamentos entre indivíduos divorciados com cônjuges solteiros é crescente, principalmente entre homens divorciados que se casam com mulheres solteiras. O índice que, em 1995, era de $4,1 \%$, foi para 6,3\% no ano de 2005 (IBGE, 2007).

Analisando-se os dados e tendo como base que eles fazem referência à situação dos brasileiros há mais de dez 
anos, e, ainda, que muitos recasamentos acabam ocorrendo de modo consensual, ou seja, sem qualquer registro ou procedimento legal, pode-se constatar que o número de divorciados que se casam novamente é muito elevado. Acrescido a isso, tem-se o aumento do índice de divórcios, de modo que se pode inferir que, atualmente, os recasamentos devam ocorrer em números mais elevados do que demonstram os dados estatísticos disponíveis.

Ao se analisar os fatores que influenciaram as mudanças dos padrões do ciclo vital, verifica-se que o aumento da expectativa de vida contribuiu para o incremento do número de recasamentos. Afinal, se antes as pessoas resignavam-se a situações infelizes, por se considerarem "muito velhas" para mudar de vida, agora elas optam pelo divórcio, buscando relacionamentos mais felizes.

Desse modo, retoma-se a hipótese de Féres-Carneiro (2003), que considera que os casais buscam o divórcio por acreditarem que o casamento possa ser algo mais do que aquilo que suas relações oferecem. Isso pode ser também compreendido com a afirmação de Carter e McGoldrick (1980/1995) de que, no recasamento, as pessoas buscam encontrar a satisfação de expectativas anteriores ao primeiro casamento.

Entretanto, diferentemente da primeira união, a família recasada encontra outros desafios que envolvem os sistemas familiares. Apresentam-se questões relacionadas à associação dos membros, ou seja, à ponderação sobre quem faz ou não parte dessa família. Ademais, há variações nos aspectos de autoridade dos pais em frente aos filhos, isto é, sobre qual é o espaço de cada um na família. Por fim, podese inferir uma alteração na percepção da administração do tempo, quer dizer, na decisão sobre a quem dedicá-lo, se aos filhos ou ao novo cônjuge, e, ainda, sobre como fazer as re-uniões entre as famílias extensas.

Carter e McGoldrick (1980/1995) salientam que o processo de recasamento envolve maior complexidade, uma vez que mais sistemas familiares estão envolvidos, de modo que a bagagem emocional e as tarefas desenvolvimentais do ciclo vital se tornam um desafio a mais para o casal que recasa. Quando há o recasamento, além dos ajustes decorrentes da união entre as famílias envolvidas, há outros elementos que se colocam em face deste novo relacionamento, tais como a família de origem, o primeiro casamento, o processo de separação/divórcio, e também o período entre os casamentos.

Diante do exposto, há que se considerar que são diversas as questões que devem ser consideradas ante a família recasada, pois, além do que foi dito, pode ocorrer que um dos cônjuges desse novo casamento ainda não tenha sido casado, de modo que, ao estabelecer um recasamento, este se depare com a vivência de outras fases do ciclo vital pelas quais ainda não tenha passado. Desse modo, não é incomum encontrar casais em que a esposa nunca foi mãe ou nem passou por um ajustamento conjugal, mas já esteja desempenhando o 'papel' de madrasta, tendo que dar conta de obrigações que envolvem desde a administração do lar até o cuidado com os filhos do cônjuge. Essas peculiaridades que envolvem o recasamento devem ser levadas em conta, tanto para se pensar em termos de prática clínica como para o desenvolvimento de novas pesquisas, uma vez que se tratam de fatores que permeiam a configuração de novos padrões e modelos de família - modelos estes cada vez mais presentes na sociedade brasileira atual.

\section{Pesquisas e Possibilidades Metodológicas}

As pesquisas brasileiras evidenciam que o divórcio já foi estudado a partir de diferentes perspectivas, tais como: na visão dos filhos (Brito, 2007; Souza, 2000; Souza \& Ramires, 2006), no papel dos avós (M. R. G. L. Araújo \& Dias, 2002), nas contribuições da mediação (Schabbel, 2005), nas crenças e valores dos adolescentes (Wagner, Falcke, \& Meza, 1997), e na vivência dos cônjuges (Féres-Carneiro, 1998, 2003). Historicamente, Souza e Ramires (2006) referem que os primeiros estudos, feitos ainda quando o divórcio não era regulamentado, traziam muito presente a idéia da patologia, devido às alterações emocionais que causava. Em outros termos, era tido como algo não normativo, que fugia à regra. Essa idéia foi (e ainda é) corroborada pela religião ${ }^{7}$, que traz a noção de imoralidade e de transgressão - como se o divórcio fosse algo ligado ao pecado, devendo ser banido do meio social.

Desse modo, as pesquisas levadas a efeito enfocavam os problemas decorrentes do divórcio, afirmando, por exemplo, que os filhos de pais divorciados apresentavam mais dificuldades que os filhos de casais não divorciados. No entanto, Schabbel (2005) refere que o tema do divórcio foi, durante muito tempo, estudado de forma fragmentada, evidenciando problemas metodológicos que podem incorrer em resultados descontextualizados da realidade das famílias.

Os estudos longitudinais são referidos como ricos na construção de novas metodologias de pesquisa nesta área. Souza e Ramires (2006) descrevem a pesquisa de Virginia Longitudinal Study, iniciada por Hetherington, na década de 60 , como uma referência em estudos longitudinais com famílias. Esse estudo analisou, durante duas décadas, quase 1.400 famílias, o que possibilitou comparar famílias casadas com famílias divorciadas, e identificar os problemas associados à separação e aqueles que eram comuns em determinados momentos do ciclo vital no contexto da sociedade americana.

A possibilidade de comparar as famílias casadas com as famílias divorciadas evidenciou que a literatura anterior exagerava nas conseqüências negativas da separação, a longo prazo, e ignorava os aspectos positivos da mesma (Souza \& Ramires, 2006). As reações negativas iniciais, vivenciadas pelos membros da família no período de divórcio, expressam a crise atual, e não necessariamente representam um comprometimento de longa duração (Souza, 2000).

\footnotetext{
${ }^{7}$ A religião é entendida, aqui, no sentido tradicional, não fazendo alusão especial a nenhum credo específico, e, sim, aos preceitos da moral e dos bons costumes, que colocavam o casamento acima de tudo, de modo que este deveria ser mantido a todo custo.
} 
Cano, D. S., Gabarra, L. M., Moré, C. O. \& Crepaldi , M. A. (2009). As Transições Familiares do Divórcio ao Recasamento no Contexto Brasileiro.

O número de divórcios modificou-se ao longo dos anos e as pesquisas nessa área ampliaram o foco de estudo. $\mathrm{Na}$ literatura nacional e internacional pesquisada, encontramse investigações referentes aos diferentes momentos do ciclo vital da família. Alguns autores enfocam o divórcio em famílias com crianças pequenas e pré-adolescentes (Ahrons, 2007; Kier, Lewis, \& Hay, 2000; Mitcham-Smith \& Henry, 2007; Ramires, 2004; Souza \& Ramires, 2006), outros focalizam as famílias com filhos adolescentes (Souza, 2000; Storksen, Roysamb, Holmen, \& Tambs, 2006), outros, ainda, abordam a rede de apoio das famílias divorciadas (M. R. G. L. Araújo \& Dias, 2002), as famílias recasadas ou com novas configurações familiares (Wagner et al., 1997; Wagner \& Féres-Carneiro, 2000), e o uso da mediação nas separações conjugais (Schabbel, 2005).

Os temas divórcio e recasamento constituem um vasto campo de pesquisas e intervenção. As possibilidades metodológicas são evidentes, seja em estudos transversais (Kier et al., 2000; Ramires, 2004; Souza, 2000; Souza \& Ramires, 2006; Wagner et al., 1997; Wagner \& Féres-Carneiro, 2000), seja nos longitudinais (Hetherington, 1991).

Os participantes das pesquisas podem ser desde famílias, crianças, adolescentes, adultos e redes de apoio até profissionais da área (advogados, assistentes sociais, médicos, professores, psicólogos). E os instrumentos utilizados podem incluir o uso de entrevistas (abertas, semi-estruturadas), escalas, inventários, frases incompletas, figuras projetivas, uso de desenho e histórias.

Há a necessidade de estudos sobre os diferentes padrões familiares para subsidiar a prática clínica e os modelos de atendimento. Os resultados dos estudos aqui citados mostram a necessidade da criação de programas de prevenção e promoção à saúde das famílias. Conforme evidenciou Travis (2003) em sua pesquisa, a maioria dos terapeutas de família pesquisados não considera relevante lançar mão de conhecimentos específicos no atendimento de famílias recasadas, constatando também que estes, em sua maioria, não têm proximidade com leituras sobre o tema. Desse modo, e diante do que foi exposto no decorrer deste artigo, ressaltam-se principalmente as peculiaridades envolvidas no recasamento, e frisa-se a importância de outros estudos brasileiros que melhor contextualizem essa realidade.

\section{Considerações Finais}

Os processos de divórcio e separação, assim como os de recasamento, mostram-se atuais e importantes no cotidiano das pessoas. Dessa forma, a construção de metodologias de intervenção condizentes com as peculiaridades e as particularidades das pessoas que vivenciam essas situações (famílias recasadas, famílias divorciadas, monoparentais) torna-se imprescindível. Contudo, para que isso se efetive de forma plausível, são necessárias pesquisas que embasem melhor as ações dos profissionais que atuam nessa área. Schabbel (2005) salienta a necessidade de pesquisas interdisciplinares, trazendo à tona a urgência do trabalho conjunto de pesquisadores de diferentes áreas do conhecimento, que possam, assim, contemplar a complexidade e as peculiaridades dos processos de divórcios e recasamentos que as famílias vivenciam.

Ao pesquisar a literatura sobre o tema, observaram-se lacunas no campo de intervenção e de pesquisa. O divórcio e o recasamento podem ocorrer em todos os momentos do ciclo vital da família, mas os estudos encontrados enfocam principalmente as famílias com filhos pequenos e adolescentes. Portanto, estudar tais transições nos demais momentos do ciclo vital se torna relevante para compreender o impacto gerado nos membros envolvidos, e as diferentes reorganizações no processo de separação e recasamento.

Acredita-se que novos estudos sejam imprescindíveis para subsidiar a prática de forma coerente com a realidade das famílias brasileiras, e que estes possam tratar, por exemplo, da fratria dos filhos com pais em processo de separação conjugal, da rede de apoio do homem e da mulher, da separação em casais homossexuais, bem como das questões que envolvem a guarda dos filhos, das alterações do papel do homem e da mulher no casamento, decorrentes das mudanças sociais, e, por fim, os desdobramentos do divórcio ao longo do tempo.

Ao final desta análise, destaca-se que as modificações nas famílias, nos últimos anos, decorrentes do divórcio e recasamento, acarretam também modificações nas concepções dos relacionamentos, em que se observa a convivência de padrões familiares "tradicionais" e "modernos". Entretanto, conforme Goldenberg (2003), apesar de o divórcio e o recasamento estarem cada vez mais presentes na atualidade, muitas pessoas que vivenciam estes relacionamentos ainda se sentem como "desviantes". Desse modo, as temáticas desenvolvidas merecem ser estudadas à luz de seus contextos e realidades, em decorrência de que, no momento atual, se descortinam diferentes valores relacionados à família, abrindo espaço para esta reflexão.

\section{Referências}

Ahrons, C. R. (1980). Redefining the divorced family: A conceptual framework for postdivorce family system reorganization. Social Work, 25, 437-441.

Ahrons, C. (2007). Family ties after divorce: Long-term implications for children. Family Process, 46(1), 53-65.

Araújo, C., \& Scalon, C. (2006). Gênero e a distância entre a intenção e o gesto. Revista Brasileira de Ciências Sociais (São Paulo), 21(62), 45-68.

Araújo, M. R. G. L., \& Dias, C. M. S. B. (2002). Papel dos avós: Apoio oferecido aos netos antes e após situações de separação/ divórcio dos pais. Estudos de Psicologia (Natal), 7(1), 91-101.

Biasoli-Alves, Z. M. M. (2004). Pesquisando e intervindo com famílias de camadas sociais diversificadas. In C. Rinaldi, I. E. Althof, \& R. G. Nitschke (Eds.), Pesquisando a família: Olhares contemporâneos (pp. 91-106). Florianópolis, SC: Papa Livros.

Brito, L. M. T. (2007). Família pós-divórcio: A visão dos filhos. Psicologia: Ciência e Profissão, 27(1), 32-45.

Brown, F. H. (2001). A família pós-divórcio (M. A. V. Veronese, Trad.). In B. Carter \& M. McGoldrick (Eds.), As mudanças no ciclo de vida familiar: Uma estrutura para a terapia familiar (pp. 321-343). Porto Alegre, RS: Artmed. (Original publicado em 1980). 
Carter, B., \& McGoldrick, M. (1995). As mudanças no ciclo de vida familiar: Uma estrutura para a terapia familiar (M. A. V. Veronese, Trad.). Porto Alegre, RS: Artes Médicas. (Original publicado em 1980)

Carter, B., \& McGoldrick, M. (2003). Novas abordagens da terapia familiar. Raça, cultura e gênero na prática clínica. São Paulo, SP: Roca.

Cerveny, C. M. O. (2002). Pensando a família sistemicamente. In C. M. O. Cerveny \& C. M. E. Berthoud (Eds.), Visitando a família ao longo do ciclo vital (pp. 15-28). São Paulo, SP: Casa do Psicólogo.

Féres-Carneiro, T. (1997). A escolha amorosa e interação conjugal na heterossexualidade e na homossexualidade. Psicologia: Reflexão e Crítica, 10(2), 351-368.

Féres-Carneiro, T. (1998). Casamento contemporâneo: O difícil convívio da individualidade com a conjugalidade. Psicologia: Reflexão e Crítica, 11(2), 379-394.

Féres-Carneiro, T. (2003). Separação: O doloroso processo de dissolução da conjugalidade. Estudos de Psicologia (Natal), 8(3), 367-374.

Fleck, A. C., \& Wagner, A. (2003). A mulher como principal provedora do sustento econômico familiar [Special issue]. Psicologia em Estudo, 8, 31-38.

Fonseca, C. (2004). Olhares antropológicos sobre a família contemporânea. In E. R. Althoff, I. Elsen, \& R. G. Nitschke (Eds.), Pesquisando a família: Olhares contemporâneos (pp. 55-68). Florianópolis, SC: Papa Livros.

Goldenberg, M. (2001). Sobre a invenção do casal. Estudos $e$ Pesquisas em Psicologia (Rio de Janeiro), 1(1), 89-104.

Goldenberg, M. (2003). Novas famílias nas camadas médias urbanas In Terceiro Encontro de Psicólogos Jurídicos (pp. 1826). Rio de Janeiro, RJ: Escola da Magistratura do Estado do Rio de Janeiro.

Goldani, A. M. (2002). Família, gênero e políticas: Famílias brasileiras nos anos 90 e seus desafios como fator de proteção. Revista Brasileira de Estudos de População, 19(1), 29-48.

Hetherington, E. M. (1991). The role of individual differences and family relationships in children's coping with divorce and remarriage. In P. A. Cowan \& M. Hetherington (Eds.) Family transitions (pp. 165-194). Hillsdale, NJ: Lawrence Erlbaum.

Instituto Brasileiro de Geografia e Estatística. (1994). Estatísticas do Registro Civil. Rio de Janeiro, RJ: Autor.

Instituto Brasileiro de Geografia e Estatística. (2007). Síntese de indicadores sociais: Uma análise das condições de vida da população brasileira 2007: Vol. 21. Estudos e Pesquisas. Informação demográfica e socioeconômica. Rio de Janeiro, RJ: Autor.

Kier, C., Lewis, C., \& Hay, D. (2000). Maternal accounts of costs and benefits of life experiences after parental separation. Psicologia: Teoria e Pesquisa, 16(3), 191-202.

Lei 6.515. (27 dez. 1977). Regula os casos de dissolução da sociedade conjugal e do casamento, seus efeitos e respectivos processos, e dá outras providências. Diário Oficial da União (Brasília, DF).

Lei $\mathrm{n}^{\mathrm{o}} 11.698$. (16 jun. 2008). Altera os arts. 1.583 e 1.584 da Lei no 10.406, de 10 de janeiro de 2002 - Código Civil, para instituir e disciplinar a guarda compartilhada. Diário Oficial da União (Brasília, DF).

Magalhães, A. S. (1993). Individualismo e conjugalidade: Um estudo sobre o casamento contemporâneo. Dissertação de Mestrado não-publicada, Pontifícia Universidade do Rio de Janeiro, RJ.
Mitcham-Smith, M., \& Henry, W. J. (2007). High-conflict divorce solutions: Parenting coordination as an innovative co-pareting intervention. The Family Journal: Counseling and Therapy for Couples and Families, 15(4), 368-373.

Nazareth, E. R. (2004). Família e divórcio. In C. M. O. Cerveny (Ed.), Família e... comunicação, divórcio, mudança, resiliência, deficiência, lei, bioética, doença, religião e drogadição (pp. 25-37). São Paulo, SP: Casa do Psicólogo.

Nock, S. L. (1981, August). Family life-cycle transitions: Longitudinal effects on family members. Journal of Marriage and the Family, 43, 703-713.

Peck, J. S., \& Manocherian, J. (2001). O divórcio nas mudanças do ciclo de vida familiar (M. A. V. Veronese, Trad.). In B. Carter \& M. McGoldrick (Eds.), As mudanças no ciclo de vida familiar: Uma estrutura para a terapia familiar (pp. 291-320). Porto Alegre, RS: Artmed. (Original publicado em 1980)

Ramires, V. R. R. (2004). As transições familiares: A perspectiva de crianças e pré-adolescentes. Psicologia em Estudo, 9(2), 183-193.

Ruther, M. (1987). Psychosocial resilience and protective mechanisms. American Journal of Orthopsychiatric, 57, 316-331.

Schabbel, C. (2005). Relações familiares na separação conjugal: Contribuições da mediação. Psicologia: Teoria e Prática, 7(1), 13-20.

Souza, R. M. (2000). Depois que papai e mamãe se separaram: Um relato dos filhos. Psicologia: Teoria e Pesquisa, 16(3), 203-211.

Souza, R. M., \& Ramires, V. R. (2006). Amor, casamento, família, divórcio... e depois, segundo as crianças. São Paulo, SP: Summus.

Storksen, I., Roysamb, E., Holmen, T., \& Tambs, K. (2006). Adolescent adjustment and well-being: Effects of parental divorce and distress. Scandinavian Journal of Psychology, 47, 75-84.

Testoni, R. J. F., \& Tonelli, M. J. F. (2006). Permanências e rupturas: Sentidos de gênero em mulheres chefes de família. Psicologia e Sociedade, 18(1), 40-48.

Travis, S. (2003). Construções familiares: Um estudo sobre a clínica do recasamento. Tese de Doutorado não-publicada, Departamento de Psicologia, Pontifícia Universidade Católica do Rio de Janeiro, RJ.

Visher, E. B., \& Visher, J. S. (1988). Old loyalties, new ties: Therapeutic strategies with stepfamilies. New York: Brunner.

Wagner, A., Falcke, D., \& Meza, E. B. D. (1997). Crenças e valores dos adolescentes acerca de família, casamento, separação e projetos de vida. Psicologia: Reflexão e Crítica, 10(1), 155-167.

Wagner, A., \& Féres-Carneiro, T. (2000). O recasamento e a representação gráfica da família. Temas em Psicologia da SBP, 8(1), 11-19.

Wendt, N. C. (2006). Fatores de risco e de proteção para o desenvolvimento da criança durante a transição para a parentalidade. Dissertação de Mestrado não-publicada, Universidade Federal de Santa Catarina, Florianópolis, SC. 